\title{
COVID-19 Induced Child Entrepreneurship in Shrimp Value Chain in Bangladesh
}

\author{
Abul Bashar, Neaz A. Hasan and Mohammad Mahfujul Haque* \\ Department of Aquaculture, Bangladesh Agricultural University, Mymensingh, Bangladesh
}

Keywords: COVID-19, shrimp industry, child labor, education sustainability, Kidpreneur

What has made child labor so common in least-developed and developing countries? The general answer is that due to poor socio-economic conditions, children have to join labor work to earn money at an early age, depriving them of knowledge and skills through formal education. Many households, because of their poor socio-economic status, force their children to go to work instead of going to school. This disrupts the productive life of numerous children, reduces their opportunities of improving their lives, and limits their chances of finding alternative employment.

Bangladesh, in the transformation from least-developed to developing country, has progressed amazingly in reducing child labor but not at an expected level. In this changeover, compulsory primary school studies have made a clear contribution. Compulsory primary education from classes 1 to 5 providing free tuition, text books, subsidiary stipend, and complementary meal blessed the country with $97 \%$ primary literacy rate and reduced child labor (till 10 years age) to nearly $0 \%$

OPEN ACCESS

Edited by:

Xiao Lin,

University of York, United Kingdom

Reviewed by:

Haojie Lian,

Taiyuan University of

Technology, China

*Correspondence: Mohammad Mahfujul Haque mmhaque.aq@bau.edu.bd

Specialty section:

This article was submitted to Multi-criteria Decision Making,

a section of the journal

Frontiers in Sustainability

Received: 03 October 2021 Accepted: 21 December 2021 Published: 21 January 2022

Citation:

Bashar A, Hasan NA and Haque MM (2022) COVID-19 Induced Child Entrepreneurship in Shrimp Value Chain in Bangladesh.

Front. Sustain. 2:788750. doi: 10.3389/frsus.2021.788750 (Quattri and Watkins, 2019). Although secondary schools (classes 6-10) provide free textbooks and provide stipends only for girls, half of the children drop out for the obligation to pay tuition fees (Khandker et al., 2013; Quattri and Watkins, 2019). These drop-out children work as low-paid workers or as unpaid workers in their own families because of poor family status or lack of access to any further vocational education. A few years back, an estimation showed that there are 5.0 million child laborers in Bangladesh (Khan and Lyon, 2015), of whom 4.6 million were enrolled in junior and secondary schools (BBS, 2015).

Due to the effect of COVID-19, the schools are closed for a long time in Bangladesh, and because of non-receipt of monthly stipend, the poor school-going children are not able to eat as much as they need. At the same time, most of the earning members of the family are struggling to make a living as they do not have the opportunity to earn during the epidemic. For the scarcity of resources to make a living in households, COVID-19 forced both school-going and non-schoolgoing children to look for work. However, because of the economic crisis caused by COVID-19, middle-aged child laborers are receiving lower wages than before, when there is no alternative to earning.

In this crisis, the children of southwest Bangladesh, particularly of Khulna Division, developed an entrepreneurial innovation in shrimp value chain. In the case of formal work and daily labor, it is common for children to experience a variety of adverse conditions, including physical, emotional, or even sexual abuse (Ahad et al., 2021). However, the shrimp value chain provides a potential atmosphere for children which gives them the opportunity to work with shrimp raw materials and by-products at a specific time of the day in a congenial workplace with very little labor. This enables small entrepreneurs to make a living and contribute to the family by avoiding forced labor. Child entrepreneurs find jobs as the end actor in the shrimp value chain and are able to reach services directly to the consumer. In just 15 shrimp and freshwater prawn markets in southwest Bangladesh, about 300 child entrepreneurs, aged 8-15 years, were found to be involved in marketing various shrimp and prawn products. These children spend $3-5 \mathrm{~h}$ a day on their business, 


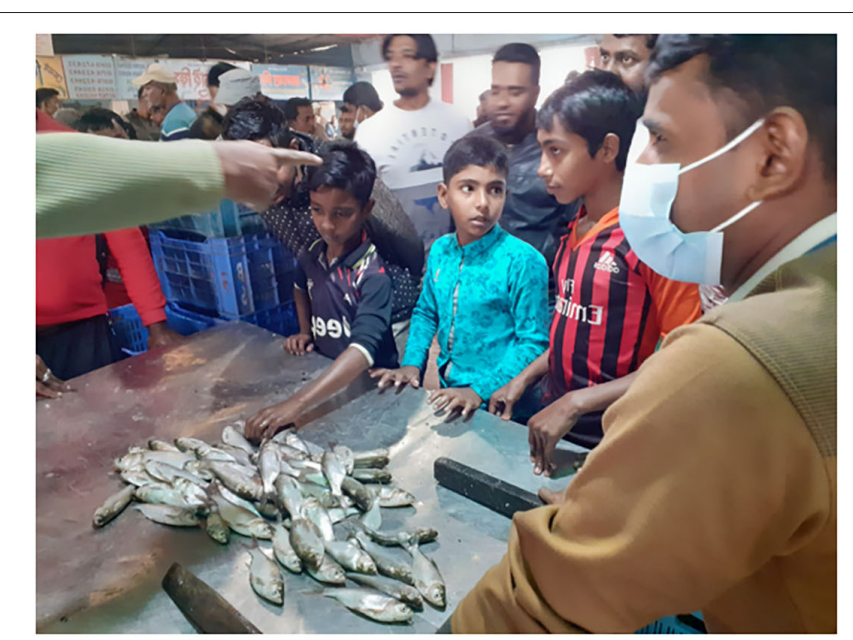

$\mathbf{A}$

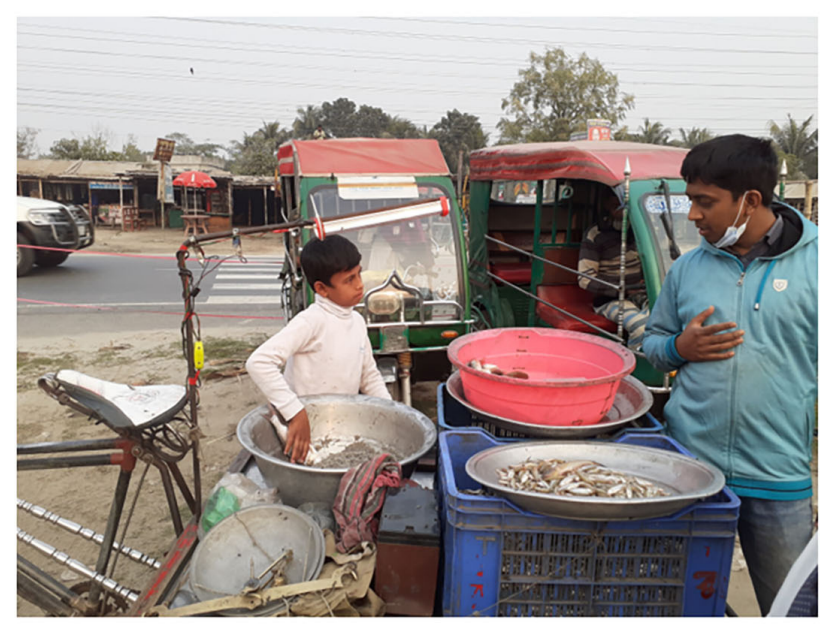

c

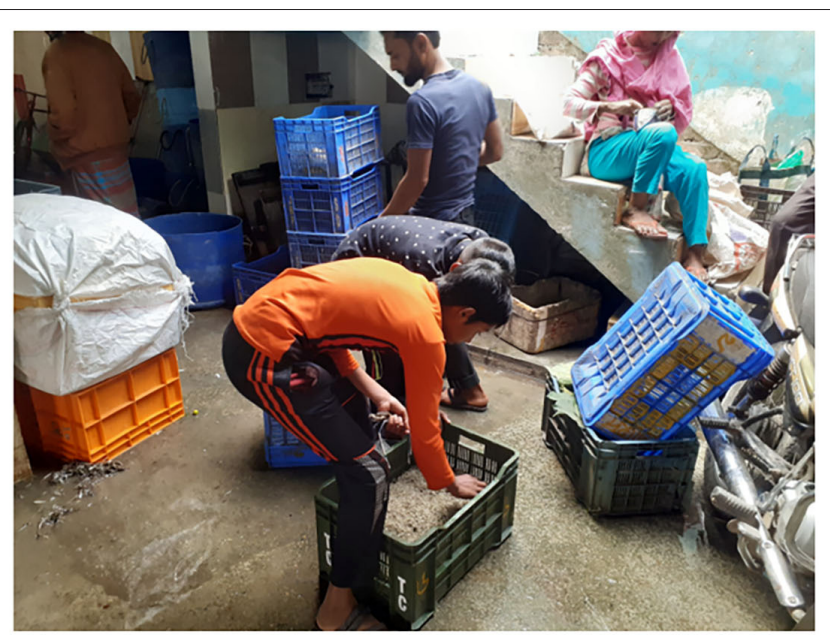

B

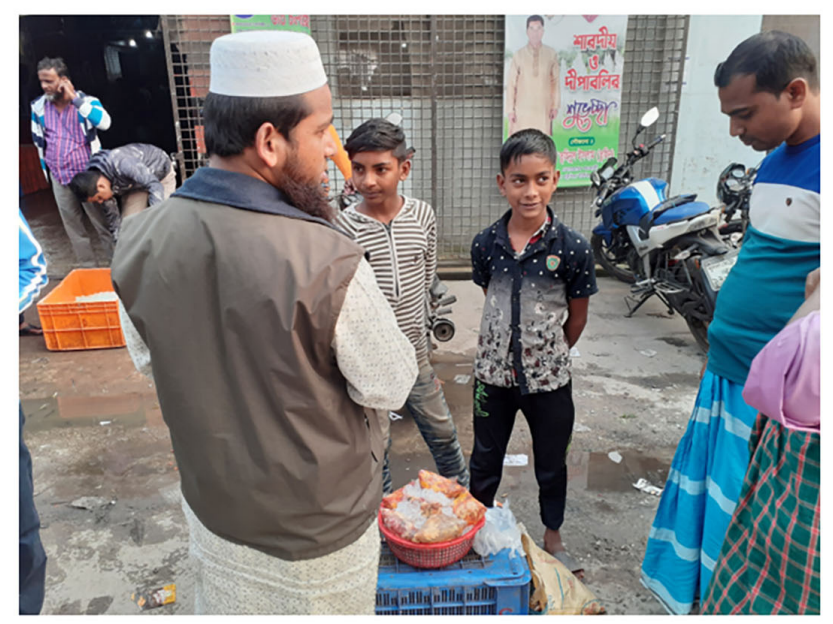

D

FIGURE 1 | Child entrepreneur contrivance in shrimp value chain of southwest Bangladesh: (A) Active engagement in auction process; (B) grading according to size species, and/or quality; (C) selling purchased remnant (after grading) shrimp or prawn and other low-cost finfish to the consumers; (D) interacting with consumers to sell by-products (prawn hepatopancreas).

including participating in tenders for product purchases (Figure 1A), grading according to species and size (Figure 1B), selling the purchased undersized shrimps and prawn, byproducts like prawn hepatopancreas (Figure 1D), and fleshy chelate legs which are thrown after initial processing. They prefer to trade cheap finfishes like Oreochromis niloticus, Hypophthalmichthys molitrix, Ctenopharyngodon idella, Labeo bata, and some other small indigenous species (Figure 1C) for making a higher profit margin. One of the main advantages of these child entrepreneurs is that they make it easier for consumers to get fresh fish products than conventional fish traders.

Child entrepreneurs often face operational risks while they unload heavy containers of purchased shrimp, prawn, and other fishes. They also suffer from economic risks for imperceptible competition with existing adult wholesalers during the auction process (see the Supplementary Video) and disturbance of regular retailers in vending. Even for any unwanted situation in the market (such as missing any stuff or any inconsistency in product volume/number) adult people find it easy to complain against these children. After all, according to children, they were comfortable in fish marketing because their involvement in the value chain was making money to contribute to their livelihoods. Swapan, a 12-year-old child, said "I need money for my family, and this business (marketing of shrimp by-products) is doing just that. There are always some difficulties, and I have to overcome them to survive." In response to the question of continuing this business after the reopening of the school, most of the children were in favor of continuing their entrepreneurial job without giving any importance to schooling. Children who have been 
admitted to high school have shown a reluctance to continue their education as it demands $6 \mathrm{~h}$ a day in school. However, primary school-going children found the schooling compatible with the shrimp business as it consumes only $3 \mathrm{~h}$ a day without hampering their entrepreneurial activities. Mamun, a junior school student, said, "By investing very little time, I can bear a lot of expenses for my family members. Business enables me to enjoy leisure time. I must continue school with this business." Concerns regarding the sustainability of education arose when Mr. Anwar (father of Mamun) was also found feeling more secure to keep his child earning from the fish business. Since the government is working diligently to ensure $100 \%$ primary and secondary literacy as part of the sustainable development goals (SDGs), keeping these poor children away from school by the shrimp business will act as a potential barrier to achieving that goal. "Kidpreneur," a new concept with less promotion as many confuse the word with child labor, can foster SDGs making a way to send back children to the schools. The word "kidpreneur" is a portmanteau of "kids" and "entrepreneur." These are the young people who start business at an early age with their own idea and are considered as the next-generation entrepreneurs. Developed countries (e.g., Australia) created "Club Kidpreneur" a not-for-profit social entrepreneurship organization with a policy to promote entrepreneurial thinking among primary school children by providing experiential learning, business literacy, and an opportunity to learn and develop business skills. Therefore, in the long-term uncertainties of the negative impacts of COVID-19, the concerned authorities should take steps to institutionalize the "Kidpreneur Policy" with special focus

\section{REFERENCES}

Ahad, M. A., Chowdhury, M., Parry, Y. K., and Willis, E. (2021). Urban child labor in Bangladesh: determinants and its possible impacts on health and education. Soc. Sci. 10, 107. doi: 10.3390/socsci10030107

BBS (2015). Child Labor Survey Bangladesh, 2013. Bangladesh Bureau of Statistics (BBS), Statistics and Information Division, Ministry of Planning, Government of the People's Republic of Bangladesh.

Khan, S., and Lyon, S. (2015). Measuring Children's Work in South Asia: Perspectives from National Household Surveys. International Labour Organization (ILO), ILO DWT for South Asia and ILO Country Office for India, New Delhi, India.

Khandker, S., Pitt, M., and Fuwa, N. (2013). Subsidy to Promote Girls Secondary Education: The Female Stipend Program in Bangladesh. enGender Impact: the World Bank's Gender Impact Evaluation Database. Washington DC: World Bank.

Quattri, M., and Watkins, K. (2019). Child labour and education - a survey of slum settlements in Dhaka (Bangladesh). World Dev. Perspect. 13, 50-66. doi: 10.1016/j.wdp.2019.02.005 on preventing temporary child entrepreneurs working in the shrimp value chain of southwest Bangladesh from dropping out of school.

\section{ETHICS STATEMENT}

The studies involving human participants were reviewed and approved by Bangladesh Agricultural University Research Systems (BAURES). Written informed consent to participate in this study was provided by the participants' legal guardian/next of kin. Written informed consent was obtained from the individual(s), and minor(s)' legal guardian/next of kin, for the publication of any potentially identifiable images or data included in this article.

\section{AUTHOR CONTRIBUTIONS}

$\mathrm{AB}$ and $\mathrm{NH}$ : conceptualization, methodology, investigation, and writing-original draft. MH: conceptualization, methodology, investigation, writing-original draft, writing-review, and editing. All authors contributed to the article and approved the submitted version.

\section{SUPPLEMENTARY MATERIAL}

The Supplementary Material for this article can be found online at: https://www.frontiersin.org/articles/10.3389/frsus. 2021.788750/full\#supplementary-material
Conflict of Interest: The authors declare that the research was conducted in the absence of any commercial or financial relationships that could be construed as a potential conflict of interest.

Publisher's Note: All claims expressed in this article are solely those of the authors and do not necessarily represent those of their affiliated organizations, or those of the publisher, the editors and the reviewers. Any product that may be evaluated in this article, or claim that may be made by its manufacturer, is not guaranteed or endorsed by the publisher.

Copyright (c) 2022 Bashar, Hasan and Haque. This is an open-access article distributed under the terms of the Creative Commons Attribution License (CC BY). The use, distribution or reproduction in other forums is permitted, provided the original author(s) and the copyright owner(s) are credited and that the original publication in this journal is cited, in accordance with accepted academic practice. No use, distribution or reproduction is permitted which does not comply with these terms. 